\title{
Sump Syndrome as a Complication of Choledochoduodenostomy
}

\author{
Motaz Qadan · Sharon Clarke · Ellen Morrow • \\ George Triadafilopoulos $\cdot$ Brendan Visser
}

Received: 28 November 2011/ Accepted: 1 December 2011/Published online: 14 December 2011

(C) Springer Science+Business Media, LLC 2011

\section{Case Presentation and Evolution}

A 71-year-old man initially underwent open cholecystectomy for biliary colic in 1990. Since then, he had been well until new symptoms began in 2009 , when he presented to a community hospital reporting intermittent epigastric pain; ultrasound and computed tomography (CT) scans revealed choledocholithiasis.

Because an endoscopic retrograde cholangiopancreatography (ERCP) and stone extraction at that hospital were unsuccessful, the patient underwent exploratory laparotomy with common bile duct (CBD) exploration, during which a CBD stone was removed and a side-to-side choledochoduodenostomy (CDD) was performed.

Several months following temporary postoperative relief of his symptoms, the patient developed recurrent episodic right upper quadrant and epigastric pain, but without associated jaundice or fever. He was referred to Stanford University Medical Center, where he was seen by a gastroenterologist for evaluation and further management.

His past medical history included atrial fibrillation, hyperlipidemia, diabetes mellitus type II, and vestibular neuritis. Drug history included metoprolol, atorvastatin,

M. Qadan $(\bowtie) \cdot$ E. Morrow · B. Visser

Department of Surgery, Stanford University School of Medicine,

300 Pasteur Drive, Stanford, CA 94305, USA

e-mail: mqadan@stanford.edu

S. Clarke

Department of Radiology, Stanford University School

of Medicine, 300 Pasteur Drive, Stanford, CA 94305, USA

G. Triadafilopoulos

Division of Gastroenterology and Hepatology, Stanford University School of Medicine, 300 Pasteur Drive, Stanford, CA 94305, USA metformin, dabigatran, dronedarone, and diltiazem. The patient had no known drug allergies. Socially, the patient did not smoke and enjoyed only occasional alcohol. There was no family history of biliary tract disease.

On examination, the patient appeared well and comfortable, was slightly underweight, and had a soft and nontender abdomen. The subcostal incision from his original surgery was visible but appeared well healed. Laboratory findings, including liver function tests, were normal (WBC 7.9, Hb 13.4, Hct 39.4, Plts 257, Na 139, K 3.9, Cl 104, CO2 23, BUN 12, Cr 0.9, PT 15.4, INR 1.3, PTT 48.5, T Bili 0.7, ALT 39, AST 16, Alk P 143, Glu 113, Ca 9.2). An echocardiogram revealed mild mitral, aortic, and tricuspid valve regurgitation, with an ejection fraction of $54 \%$. Magnetic resonance cholangiopancreatography (MRCP) revealed a grossly dilated and tortuous CBD, as well as dilated common hepatic and intrahepatic ducts (Fig. 1a). A fluid-debris level was also seen in the CBD (Fig. 1b).

Endoscopy revealed a patent side-to-side CDD anastomosis that could be entered with the gastroscope (Fig. 2). Moderate amounts of vegetable debris were seen in the $\mathrm{CBD}$, and were removed using a rat-toothed forceps (Fig. 3). Using a duodenoscope, the CBD was also cannulated through the ampullary orifice and contrast injection showed an 18-mm-wide CBD with contrast extravasation through the stoma. Filling defects revealed further debris in the distal CBD, which were cleared using a balloon catheter through the CDD.

Following ERCP, the patient was immediately relieved of his symptoms. However, within a few days, the symptoms recurred, and, again, included epigastric pain without jaundice or fever. Multiple further ERCPs were necessary, each revealing similar findings of vegetable debris within the CBD. Despite clearing the CBD during each procedure, the debris re-accumulated and symptoms always recurred. 

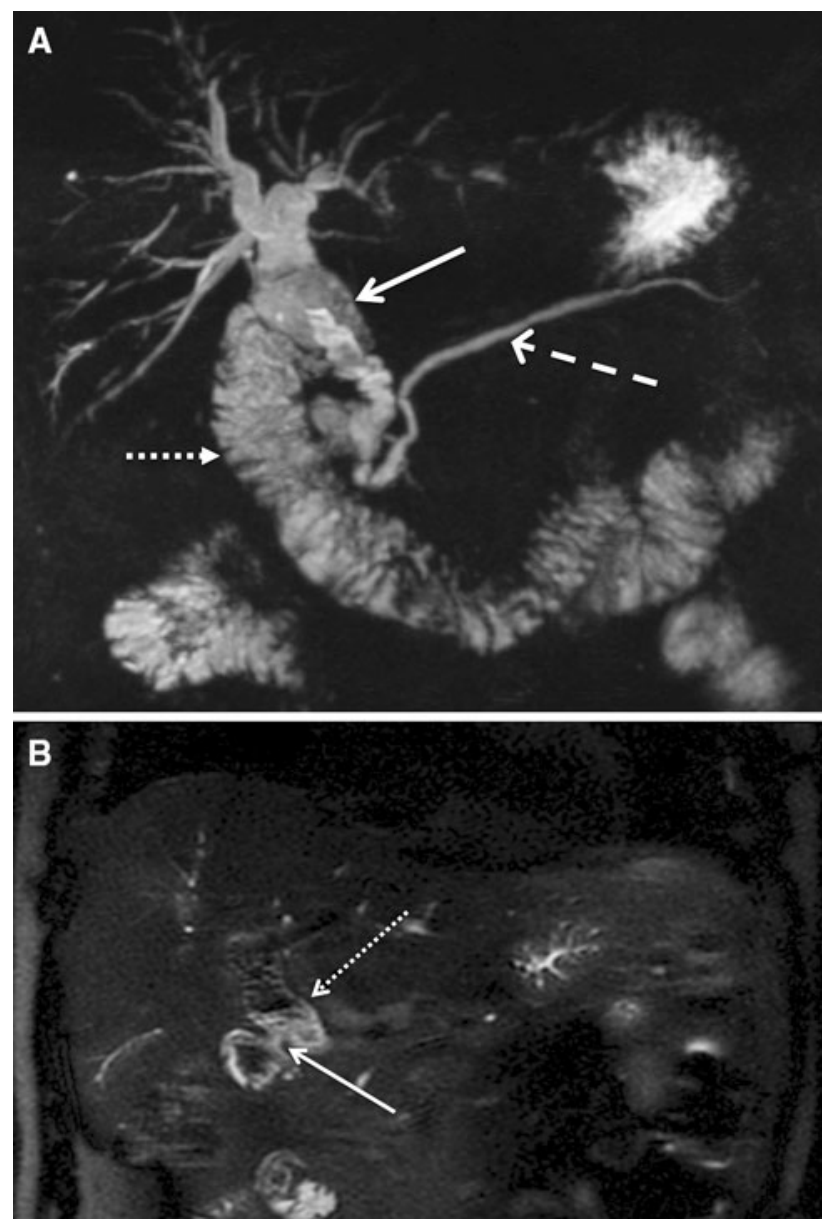

Fig. 1 a A grossly dilated and tortuous common bile duct (CBD) (solid arrow) is seen on T2-weighted coronal magnetic resonance imaging (MRI). The common hepatic and intrahepatic ducts are also dilated. The pancreatic duct (dashed arrow) and duodenum (dotted arrow) appear normal in caliber. b Fluid-debris level in the CBD (dotted arrow) and the anastomosis between the CBD and duodenum (solid arrow) can be appreciated

Finally, the patient was referred to the hepatopancreaticobiliary team at Stanford University Medical Center for surgical correction of the underlying cause of his persistent symptoms, which were consistent with the diagnosis of sump syndrome.

Over the ensuing weeks, the patient underwent a Rouxen-Y hepaticojejunostomy (Fig. 4a-c). Extensive lysis of adhesions was performed in order to identify the biliary anatomy. A patulous CBD was identified, and appeared filled with vegetable debris and mucous. The CBD was resected and the duodenostomy was closed. A Roux-en-Y hepaticojejunostomy was made near the hepatic confluence. There were no perioperative complications. The patient tolerated the procedure well and was discharged home with no further episodes of pain.

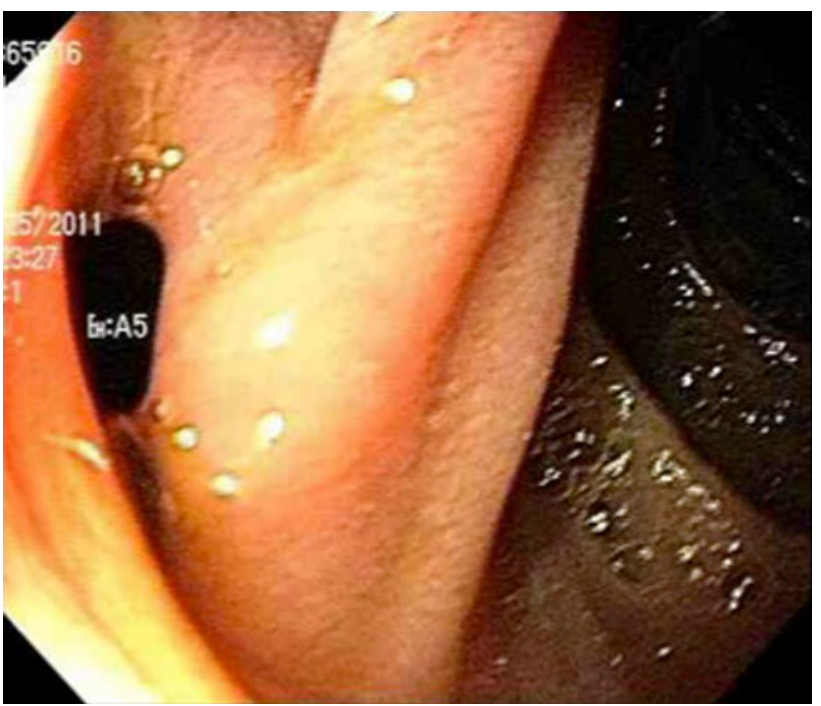

Fig. 2 Endoscopic imaging reveals a patent choledochoduodenostomy (CDD) on the left side of the image; the duodenum continues to the right

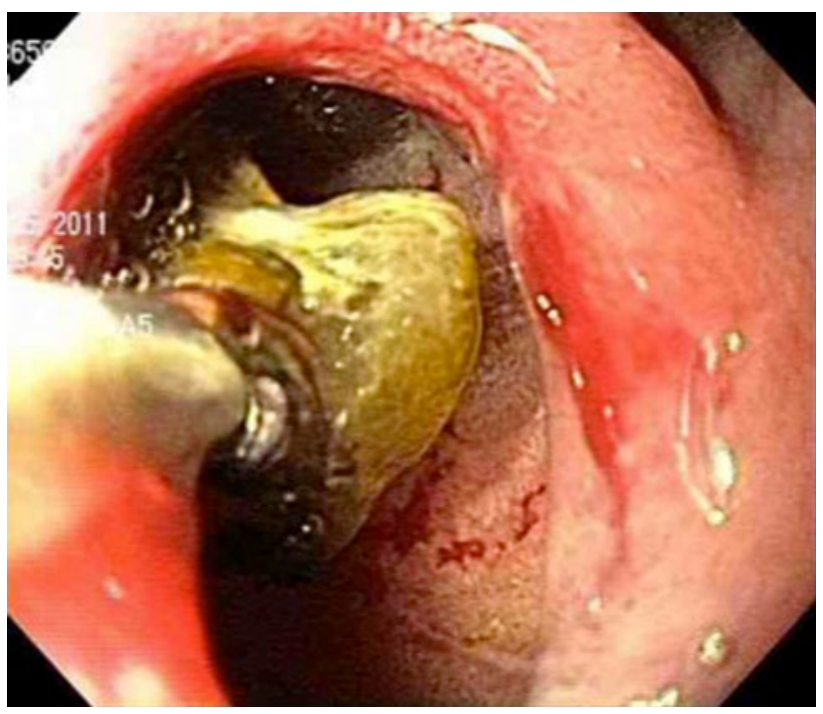

Fig. 3 Vegetable debris are removed with rat-toothed forceps from within the blind distal CBD segment

\section{Discussion}

On July 23 1888, a middle-aged woman underwent cholecystectomy by Dr. Bernhard Riedel. By December of that year, she remained jaundiced. Riedel was concerned about a residual stone, and opted to re-explore the patient. At surgery, he removed several CBD stones and performed a side-to-side anastomosis between the CBD and duodenum, thus, documenting the first ever CDD. Unfortunately, the patient died several hours later due to an anastomotic leak, which was identified at autopsy. The cause was probably persistent stones [1]. 

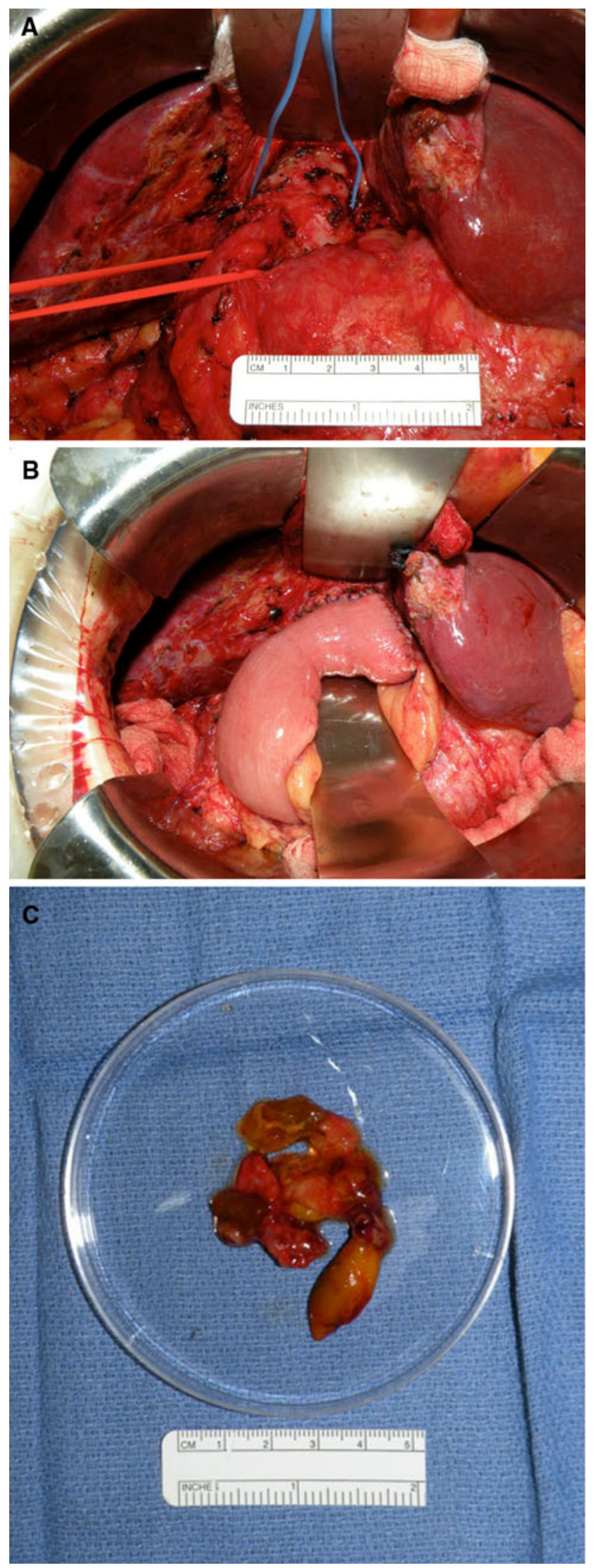

4 Fig. 4 a Operative exploration reveals the intact CDD between the dilated CBD (blue loop) and duodenum (red loop). b The CDD is revised to a Roux-en-Y hepaticojejunostomy. c An undigested bean within the resected CBD (smooth lump in the lower right segment of the image) can be appreciated

The first successful CDD was completed 2 years later by Sprengel in 1891 [2]. Since then, it has been widely described as a biliary drainage procedure, with promising to excellent results reported in most series. In 1928, Florcken reported 100 cases of CDD with excellent results, but stressed the importance of a widely patent anastomosis [3]. In 1945, Sanders reported his series of 25 patients who underwent CDD [4], and, in 1991, the first successful laparoscopic CDD for benign CBD obstruction was reported [5].

Despite significant progress in performing CDD, it is a procedure that is less commonly performed today. Nonetheless, patients continue to present with complications related to CDD. When performed, the anastomosis is fashioned in an end-to-side configuration. Although it is well tolerated by acutely ill and elderly or frail patients $[6,7]$, it has been principally surpassed by ERCP as the primary modality for addressing obstructive CBD disease. Laparoscopic and open CBD exploration are first-line surgical procedures, and, if drainage of the $\mathrm{CBD}$ is still not possible, other options, including Roux-en-Y choledochojejunostomy or hepaticojejunostomy, will usually be performed. Recognized indications for performing CDD include, most classically, benign stricturing disease of the $\mathrm{CBD}$, which results in bile stasis and the potential for primary stone formation. In addition, CDD is carried out as a salvage procedure for large or numerous distal primary CBD stones which cannot be cleared by endoscopic techniques [8]. Finally, CDD is performed as a palliative procedure for unresectable distal CBD cancer, which allows the drainage of bile by bypassing the diseased and obstructed biliary segment [9]. The only absolute contraindication to the procedure is duodenal obstruction.

For CDD to be successful and with few long-term complications, the procedure requires the $\mathrm{CBD}$ to be at least $1.2 \mathrm{~cm}$ at the time of surgery, in order to prevent stricturing at the anastomosis and to maintain adequate biliary drainage [9]. The anastomosis is often created at the most distal possible portion of the CBD. The duodenum is reflected medially (mobilized with a Kocher maneuver) and the CBD is dissected clear of surrounding structures, in order to provide adequate length for a tension-free anastomosis. A duodenotomy and choledochotomy (each approximately $2 \mathrm{~cm}$ ) are subsequently made in perpendicular axes. Finally, a side-to-side single-layered anastomosis is created with absorbable suture following exploration and clearance of the CBD. 
Morbidity and mortality rates following CDD are quoted at 23 and 3\%, respectively [8]. Mortality has often been due to medical complications in reported case series, including pulmonary embolus and myocardial infraction. Morbidity, on the other hand, is often due to cholangitis, as well as the most feared long-term complication, sump syndrome. While the two complications may coexist, sump syndrome, by definition, does not require a diagnosis of cholangitis.

Cholangitis following CDD may occur in 0-6\% of cases and is thought to be related to the duodenal reflux of bacteria into the biliary tree [8]. However, since biliary bacterial contamination occurs universally following CDD [10], there must also be concomitant impairment in biliary drainage in order to result in elevated biliary tree pressures that are required for the spillover of bacteria-rich bile into the systemic circulation [11, 12]. It follows that, for drainage to be impaired with CDD, stenosis of the anastomotic site is necessary, with ampullary drainage already previously limited.

Sump syndrome is an uncommon complication to the infrequently carried out side-to-side CDD. The segment of CBD between the anastomosis and the ampulla of Vater acts as a reservoir for stagnant bile with associated formation of debris, food, stones, and bacteria. Although the CDD remains widely patent, this also allows large food particles to enter the CBD, where they fall into its distaldependent portion and are entrapped. Without concomitant impairment of biliary drainage through the CDD, cholangitis is unlikely to develop in this setting alone. Symptoms of sump syndrome include persistent pain with nausea and, occasionally, vomiting. It is the presence of symptoms following bile stagnation within the bile duct that characterize the syndrome. Reported complications of sump syndrome may include cholangitis, pancreatitis, hepatic abscesses, and secondary biliary cirrhosis, and likely correlate with the extent and duration of biliary stasis and subsequent obstruction. Occasionally, sump stagnation may result in bile salt deconjugation, leading to bacterial proliferation, malabsorption, and steatorrhea [10, 12, 13].

Studies report a low sump syndrome rate of $2.5 \%$ [3], ranging from 0 to $9.6 \%$ in the largest series [12-14]. Although sump syndrome does not require cholangitis or hepatic abscess formation for diagnosis, some series have relied on these complications for diagnosis. The true incidence of sump syndrome may, therefore, be under-reported [3]. The syndrome is thought to result in abnormal liver function tests in some cases [12]. Additional laboratory abnormalities depend on further complications, such as abscess formation and pancreatitis.

Under normal circumstances following CDD, imaging should reveal a patent CDD with air in the biliary tree or barium following contrast studies [15], with "the more barium the better," as Florcken stated in 1928, highlighting the importance of a widely patent stoma [3]. In sump syndrome, imaging may reveal little barium flow with visualization of the 'sump,' with or without evidence of debris and/or stones. Debris or stones in the distal CBD are the most frequent and most indicative CT and MRCP findings of the sump syndrome. Thickening and/or enhancement of the bile duct walls on CT or MRCP reflecting cholangitis or inflammation from an adjacent stone should be considered suspicious. Other suggestive findings include dilated bile and/or pancreatic ducts, liver abscesses, and pancreatitis [15].

Once the diagnosis is made, the treatment of sump syndrome usually begins with endoscopic sphincterotomy in order to decompress the CBD distally at the level of the ampulla, and this has been reported with good initial success rates [16-19]. However, endoscopic management may fail because of previous heavy stone burden or benign stricturing disease that necessitated CDD in the first place, or because of new large food particles that pass through the stoma into the CBD which cannot be cleared through a large enough sphincterotomy, as in this case. If endoscopic management is not successful, or repeat endoscopic intervention is required to clear re-accumulating debris, surgical options include revision of the CDD to a Roux-en-Y hepaticojejunostomy, with resection of the distal portion of the CBD. In the setting of cholangitis with sump syndrome, endoscopic balloon dilation of the stoma may also be necessary.

\section{Key Points}

- $\mathrm{CDD}$ is an uncommon biliary drainage procedure that may be performed for complex benign stone disease and malignant biliary obstruction.

- Its two most common complications are cholangitis and sump syndrome, both of which occur infrequently.

- Sump syndrome occurs due to the stagnation of bile and debris in the blind distal CBD segment (sump).

- The treatment of sump syndrome is endoscopic sphincterotomy with or without revision surgery, including Roux-en-Y hepaticojejunostomy.

Conflict of interest The authors have no conflicts of interest, financial or otherwise, to disclose.

\section{References}

1. Riedel H. Uber den zungenfoermigen fortastz des recchten lebberlappens und seine pathognostiche bedentung fur die, erkrankungen der gallenblose nebst bemerkungen gallenstein operationen. Berl Klin Wochenschr. 1888;25:577. 
2. Sprengel O. Uber einen fall von extirpation der gallenblase mit anlegung einer kommunikation zwischen ductus choledochus und duodenum. Arch Klin Chir. 1891;124:1913.

3. Leppard WM, Shary TM, Adams DB, Morgan KA. Choledochoduodenostomy: is it really so bad? J Gastrointest Surg. 2011;15:754.

4. Sanders RL. Indications for and value of choledochoduodenostomy. Ann Surg. 1946;123:847.

5. Jeyapalan M, Almeida JA, Michaelson RL, Franklin ME Jr. Laparoscopic choledochoduodenostomy: review of a 4-year experience with an uncommon problem. Surg Laparosc Endosc Percutan Tech. 2002;12:148.

6. Birkenfeld S, Serour F, Dona G, Krispin M. Choledochoduodenostomy for benign biliary tract disease in the elderly. Am Surg. 1987;53:658.

7. Lygidakis NJ. Surgical approaches to recurrent choledocholithiasis. Choledochoduodenostomy versus T-tube drainage after choledochotomy. Am J Surg. 1983;145:636.

8. de Aretxabala X, Bahamondes JC. Choledochoduodenostomy for common bile duct stones. World J Surg. 1998;22:1171.

9. Zinner MJ Jr, Ashley SW. Maingot's Abdominal Operations. 11th ed. New York: McGraw-Hill; 2007.

10. Thomas E, Grant AK, Holford M, Ringwood D, Derrington AW, Magarey JR. Bacterial flora in the duodenum of patients after biliary fenestration. Br J Surg. 1973;60:107.
11. Huang T, Bass JA, Williams RD. The significance of biliary pressure in cholangitis. Arch Surg. 1969;98:629.

12. Baker AR, Neoptolemos JP, Carr-Locke DL, Fossard DP. Sump syndrome following choledochoduodenostomy and its endoscopic treatment. Br J Surg. 1985;72:433.

13. de Almeida AM, Cruz AG, Aldeia FJ. Side-to-side choledochoduodenostomy in the management of choledocholithiasis and associated disease. Facts and fiction. Am J Surg. 1984;147:253.

14. Madden JL, Chun JY, Kandalaft S, Parekh M. Choledochoduodenostomy: an unjustly maligned surgical procedure? Am J Surg. 1970;119:45.

15. Hawes DR, Pelsang RE, Janda RC, Lu CC. Imaging of the biliary sump syndrome. AJR Am J Roentgenol. 1992;158:315.

16. Siegel JH. Duodenoscopic sphincterotomy in the treatment of the "sump syndrome". Dig Dis Sic. 1981;26:922.

17. Marbet UA, Stalder GA, Faust H, Harder F, Gyr K. Endoscopic sphincterotomy and surgical approaches in the treatment of the 'sump syndrome'. Gut. 1987;28:142.

18. Hallstone A, Triadafilopoulos G. "Spontaneous sump syndrome": successful treatment by duodenoscopic sphincterotomy. Am J Gastroenterol. 1990;85:1518.

19. Caroli-Bosc FX, Demarquay JF, Peten EP, et al. Endoscopic management of sump syndrome after choledochoduodenostomy: retrospective analysis of 30 cases. Gastrointest Endosc. 2000; $51: 180$. 